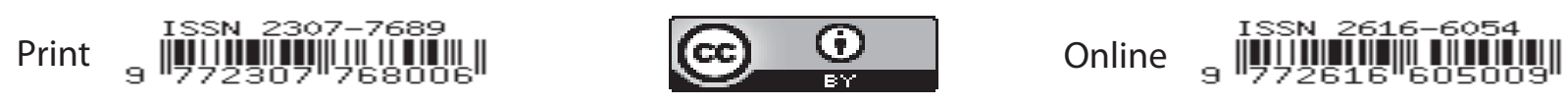

\section{Mediscope}

ORIGINAL ARTICLE

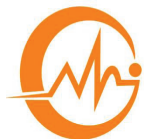

The Journal of GMC

\title{
Prescribing pattern of antidepressant drugs in two teaching hospitals in Bangladesh
}

\author{
B Islam¹, I Shahriar2, T Jannat ${ }^{3}$
}

\begin{abstract}
As depression is a major public health problem, a drug utilization study is beneficial in clinical practice for rational prescribing and helpful for minimizing the medication errors. In our country antidepressant drugs are commonly used in treatment of depression. To obtain information regarding the prescribing pattern of antidepressant drugs in accordance with WHO prescribing indicators, a descriptive cross sectional study was carried out at psychiatry out-patient department of Sir Salimullah Medical College \& Hospital(SSMCH) and Dhaka Medical College Hospital(DMCH) in Bangladesh. A total of 300 (150 in each hospital) prescriptions were analyzed by using WHO prescribing indicators and Essential Drug List of Bangladesh. Among 300 patients with major depression $(64 \%, 58.66 \%)$, females were $(53.33 \%, 58 \%)$ and males were $(46.67 \%$, $42 \%$ ) which is commonly seen between the age group 18-27 years in DMCH and SSMCH respectively. Most commonly prescribed antidepressant as monotherapy was sertraline $(58.02 \%$, $70 \%)$. Average number of drugs per prescription was $(2.24 \pm 0.93,2.12 \pm 0.83)$. Percentage of drug prescribed by generic name and percentage of encounters with an injection prescribed was nil in both hospitals. Percentage of drugs prescribed from Essential Drug List of Bangladesh was $(37.5 \%, 25.47 \%)$ in $\mathrm{DMCH}$ and SSMCH respectively. Prescribing pattern of antidepressant drugs in both teaching hospitals are almost similar in accordance with WHO prescribing indicators.
\end{abstract}

Key words: antidepressant drugs, rational prescribing, drug utilizations.

Introduction:

The World Health Organization (WHO) has reported that depression is the leading cause of disability in the world, and by 2020 , it will be the second greatest public health concern. ${ }^{1}$ In Bangladesh, the lifetime prevalence of major depressive disorder is $4.6 \% .^{2}$ Over the years antidepressant prescribing patterns have undergone revolution with rational prescribing practice being implemented globally, resulting in conventional drugs like tricyclic antidepressants (TCAs) and mono-amine oxidase inhibitors (MAOIs) being gradually replaced by selective serotonin reuptake inhibitors (SSRIs), serotonin norepinephrine reuptake inhibitors (SNRIs) and novel antidepressants. ${ }^{3}$ Prescribing patterns need to be evaluated periodically to increase the

1. Dr. Baishakhi Islam, M.B.B.S., M. Phil, Assistant Professor, Department of Pharmacology \& Therapeutics, Gazi Medical College, Khulna.

2. Prof. Dr. Iram Shahriar, M.B.B.S., M. Phil, Professor \& Head, Department of Pharmacology \& Therapeutics, Sir Salimullah Medical College, Dhaka.

3. Dr. Tamanna Jannat, M.B.B.S., M. Phil, Assistant Professor, Department of Pharmacology \& Therapeutics, Bikrampur Bhuiya Medical College, Munshigonj. 
therapeutic efficacy, decrease adverse effects and provide feedback to prescribers. ${ }^{4}$ The present study has been carried out to obtain information regarding the current prescribing pattern of antidepressant drug by the medical prescribers in two tertiary level hospital in Bangladesh by applying some WHO prescribing indicators with a view to assessing rational or inappropriate prescribing. Prescribing indicators include the a) Average number of drugs per encounter $b$ ) Percentage of drugs prescribed by generic name c) Percentage of encounters with an antibiotic prescribed d)Percentage of encounters with an injection prescribed e) Percentage of drugs prescribed from Essential Drug List or formulary. ${ }^{5}$

\section{Methodology:}

The study was a descriptive cross sectional observation study carried out in department of Pharmacology \& Therapeutics of SSMC from period of June 2015 to June 2016, over one year. Patients attending in psychiatry outpatient department of Dhaka Medical College Hospital (DMCH) and Sir Salimullah Medical College and Hospital (SSMCH) were the study population. A total of 300 patients (150 in each hospitals) of depressive illness attending psychiatry OPD in this study were selected following purposive sampling technique and analyzed as per the WHO prescribing indicators. The inclusion criteria were age group of $18-60$ years for both sexes with an established diagnosis of depression by clinician and patients willing to participate in the study whereas depression existing with other disorders like bipolar disorder and patients not willing to participate in the study were excluded.

A preformed customized pro-forma was used to collect the required drug information and analyzed on the basis of WHO prescribing indicators and essential drug list of Bangladesh. Demographic details, family history, medical history, and other general information was taken in that questionnaire. Data was analyzed by using Microsoft Excel 2007 and IBM SPSS 17.0
Results and Observation:

Among 300 patients from both $\mathrm{DMCH}$ (150) and $\operatorname{SSMCH}(150)$, most of the patients belonged to the age group ranging from $18-27$ years, $52.66 \%$ in $\mathrm{DMCH}$ and $48 \%$ in $\mathrm{SSMCH}$ and among them majority of the patient were female. Age distribution and other demographic details are shown in [Table 01]. Major depressive disorder was the most common disorder (64\%, 58.66\%), followed by Generalized Anxiety Disorder (24\%, 28.66\%) and obsessive compulsive disorder $(7.33 \%, 10 \%)$ in $\mathrm{DMCH} \& \mathrm{SSMCH}$ respectively [Table 02]. Selective serotonin reuptake inhibitors (SSRIs) were the most commonly prescribed drugs $(54 \%, 60 \%)$ followed by tricyclic antidepressants (TCAs) (28\%, 20\%), SNRIs $(10 \%, 4.6 \%)$ and atypical group $(8 \%, 15.33 \%)$ in $\mathrm{DMCH} \& \mathrm{SSMCH}$ respectively [Table 03]. Amongst SSRIs, most frequently prescribed drug was sertraline $(58.02 \%, 70 \%)$ followed by escitalopram $(20.99 \%, 22.22 \%)$, citalopram (12.34\%, $4.44 \%)$ and fluoxetine $(8.64 \%, 3.33 \%)$. Amongst TCAs, amitriptyline $(61.90 \%$, $43.33 \%$ ) was commonly prescribed followed by Imipramine $(21.42 \%, 16.66 \%)$, clomipramine $(16.66 \%, 40 \%)$. SNRIs (venlafaxine $100 \%$ in both) and Atypical (mirtazapine $100 \%$ in both) being the other most frequently used drug [Fig.01]. Along with antidepressants, the patients were also prescribed anxiolytic drugs $(35.41 \%, 35.84 \%)$, antipsychotic drugs $(1.19 \%, 3.45 \%)$ and other drugs(PPI, Vitamin) $(18.75 \%, 13.52 \%)$.

Different $\mathrm{WHO}$ recommended prescribing indicators are showed in [Table 04] as following: average number of drugs per prescription was $(2.24 \pm 0.93,2.12 \pm 0.83)$. No drugs were prescribed in generic form. No injectable medicine was prescribed in this study. Only $37.5 \%(\mathrm{DMCH})$ and $25.47 \%(\mathrm{SSMCH})$ drugs were prescribed from Essential Drug List of Bangladesh, 2008. The percentage of prescription were complete $(100 \%)$ with respect to dose, duration \& frequency in both $\mathrm{DMCH}$ and in SSMCH 
Table 1: Demographic profile of study population

\begin{tabular}{|c|c|c|c|}
\hline \multicolumn{2}{|c|}{ Characteristic of study population } & $\begin{array}{c}\text { DMCH }(n=150) \\
\text { No. }(\%)\end{array}$ & $\begin{array}{c}\text { SSMCH }(n=150) \\
\text { No. }(\%)\end{array}$ \\
\hline \multirow{4}{*}{$\begin{array}{l}\text { Age } \\
\text { (yrs) }\end{array}$} & $18-27$ & $79(52.66 \%)$ & $72(48 \%)$ \\
\hline & $28-37$ & $38(25.33 \%)$ & $46(30.66 \%)$ \\
\hline & $38-47$ & $21(14 \%)$ & $18(12 \%)$ \\
\hline & $48-57$ & $12(8 \%)$ & $14(9.33 \%)$ \\
\hline \multirow{2}{*}{ Sex } & Male & $70(46.67 \%)$ & $63(42 \%)$ \\
\hline & Female & $80(53.33 \%)$ & $87(58 \%)$ \\
\hline \multirow{2}{*}{ Marital status } & Married & $82(54.66 \%)$ & $78(52 \%)$ \\
\hline & Unmarried & $68(45.33 \%)$ & $72(48 \%)$ \\
\hline \multirow{5}{*}{ Occupation } & Housewife & $68(45.33 \%)$ & $72(48 \%)$ \\
\hline & Unemployed & $35(23.33 \%)$ & $42(42 \%)$ \\
\hline & Student & $22(14.66 \%)$ & $16(10.66 \%)$ \\
\hline & Businessman & $18(12 \%)$ & $09(6 \%)$ \\
\hline & Service holder & $07(4.66 \%)$ & $11(7.33 \%)$ \\
\hline \multirow{5}{*}{$\begin{array}{l}\text { Level of } \\
\text { education }\end{array}$} & No formal education & $48(32 \%)$ & $42(28 \%)$ \\
\hline & Primary & $20(13.33 \%)$ & $27(18 \%)$ \\
\hline & Secondary & $30(20 \%)$ & $36(24 \%)$ \\
\hline & SSC/HSC & $34(22.66 \%)$ & $31(20.66 \%)$ \\
\hline & Graduate & $18(12 \%)$ & $14(9.33 \%)$ \\
\hline \multirow{2}{*}{ Residence } & Rural & $112(74.66 \%)$ & $123(82 \%)$ \\
\hline & Urban & $38(25.33 \%)$ & $27(18 \%)$ \\
\hline \multirow{3}{*}{$\begin{array}{l}\text { Socio-economic } \\
\text { status (Income) }\end{array}$} & Low (<Tk.10000/month) & $95(63.33) \%$ & $80(53.33 \%)$ \\
\hline & $\begin{array}{l}\text { Medium (Tk.10000- } \\
\text { 20000/month) }\end{array}$ & $40(26.66 \%)$ & $61(40.67 \%)$ \\
\hline & High (>Tk.20000/month) & $15(10 \%)$ & $09(6 \%)$ \\
\hline
\end{tabular}

Table 2: Various disorders where antidepressant drugs were prescribed

\begin{tabular}{|l|c|c|}
\hline \multicolumn{1}{|c|}{ Types of psychiatric disorder } & $\begin{array}{c}\text { DMCH (n= 150) } \\
\text { No. (\%) }\end{array}$ & $\begin{array}{c}\text { SSMCH (n= 150) } \\
\text { No. (\%) }\end{array}$ \\
\hline Major Depressive Disorder (MDD) & $96(64 \%)$ & $88(58.66 \%)$ \\
\hline Generalized Anxiety Disorder (GAD) & $36(24 \%)$ & $43(28.66 \%)$ \\
\hline Obsessive Compulsive Disorder (OCD) & $11(7.33 \%)$ & $15(10 \%)$ \\
\hline Chronic pain & $07(4.67 \%)$ & $04(2.67 \%)$ \\
\hline
\end{tabular}

Table 3: Distribution of different classes of antidepressant drugs

\begin{tabular}{|c|c|c|c|}
\hline \multicolumn{2}{|c|}{ Antidepressant drugs } & $\begin{array}{c}\text { DMCH }(n=150) \text { No. } \\
(\%)\end{array}$ & $\begin{array}{c}\text { SSMCH }(n=150) \\
\text { No. }(\%)\end{array}$ \\
\hline \multirow{5}{*}{ SSRIS } & Sertraline & $47(58.02 \%)$ & $63(70 \%)$ \\
\hline & Escitalopram & $17(20.99 \%)$ & $20(22.22 \%)$ \\
\hline & Citalopram & $10(12.34 \%)$ & $4(4.44 \%)$ \\
\hline & fluoxetine & $7(8.64 \%)$ & $3(3.33 \%)$ \\
\hline & Subtotal & $81(54 \%)$ & $90(60 \%)$ \\
\hline \multirow{4}{*}{ TCAs } & Amitriptyline & $26(61.90 \%)$ & $13(43.33 \%)$ \\
\hline & Imipramine & $9(21.42 \%)$ & $5(16.66 \%)$ \\
\hline & clomipramine & $7(16.66 \%)$ & $12(40 \%)$ \\
\hline & Subtotal & $42(28 \%)$ & $30(20 \%)$ \\
\hline \multirow{2}{*}{ SNRIs } & venlafaxine & $15(100 \%)$ & $7(100 \%)$ \\
\hline & Subtotal & $15(10 \%)$ & $7(4.67 \%)$ \\
\hline \multirow{2}{*}{ Atypical group } & mirtazapine & $12(100 \%)$ & $23(100 \%)$ \\
\hline & Subtotal & $12(8 \%)$ & $23(15.33 \%)$ \\
\hline
\end{tabular}




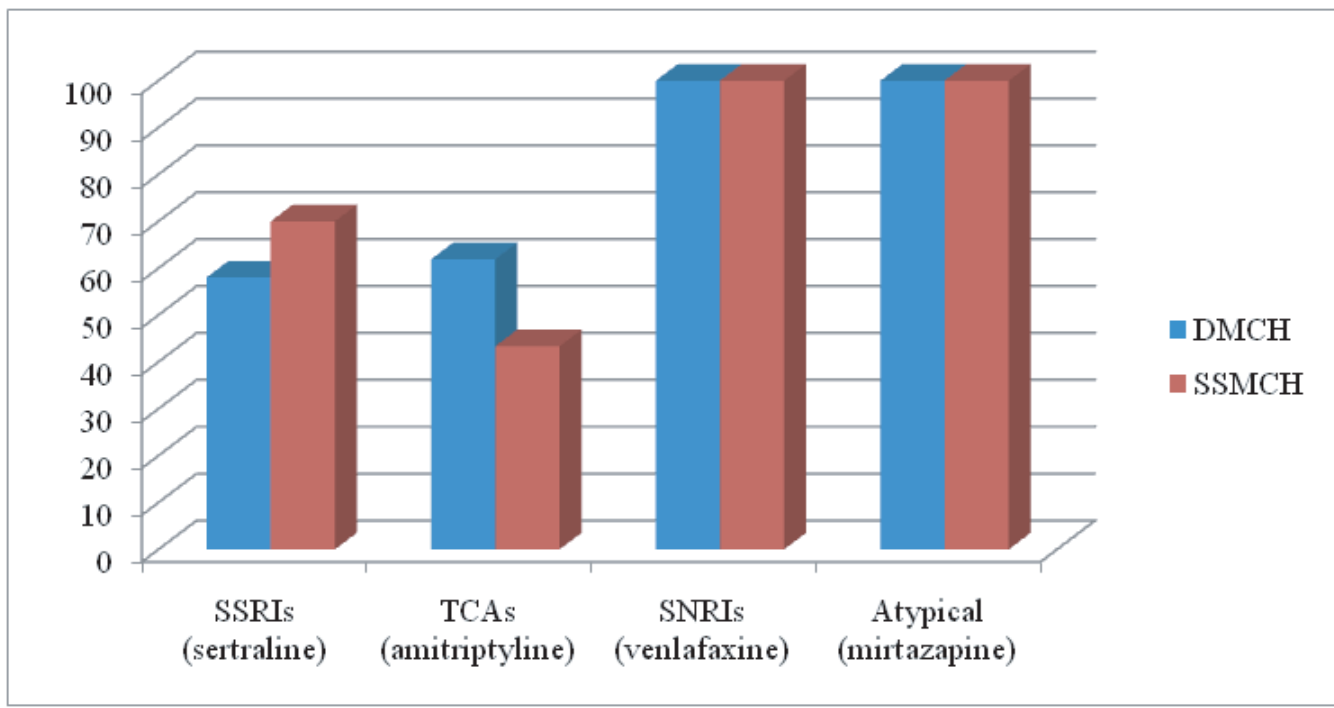

Figure 1 : Most commonly prescribed antidepressant drugs

Table 4: Prescribing pattern of antidepressant drugs according to WHO prescribing indicators

\begin{tabular}{|l|l|l|l|}
\hline WHO recommended prescribing indicators & $\begin{array}{l}\text { DMCH } \\
\mathbf{( n = 1 5 0 )}\end{array}$ & $\begin{array}{l}\text { SSMCH } \\
(\mathbf{n = 1 5 0 )}\end{array}$ & P-Value \\
\hline Average number of drugs prescribed per encounter & $2.24 \pm 0.93$ & $2.12 \pm 0.83$ & 0.12 \\
\hline Percentage of the drugs prescribed by generic name & $0 \%$ & $0 \%$ & NS \\
\hline Percentage of encounters with an injection prescribed & $0 \%$ & $0 \%$ & NS \\
\hline Percentage of encounters with an antibiotic prescribed & NA & NA & NA \\
\hline $\begin{array}{l}\text { Percentage of drugs prescribed from Essential Drug List } \\
\text { of Bangladesh }\end{array}$ & $37.5 \%$ & $25.47 \%$ & $\begin{array}{l}0.00094 \\
\text { (Significant) }\end{array}$ \\
\hline
\end{tabular}

\section{Discussion:}

The present study aimed at evaluating the current prescription patterns of antidepressants among physicians and prevention of irrational use of drugs by reviewing the prescriptions in outpatient department by following $\mathrm{WHO}$ prescribing guidelines.

Out of total 300 prescriptions analyzed, 150 from $\mathrm{DMCH}$ and 150 from SSMCH, female patients formed the majority $(53.33 \%, 58 \%)$ compared to male $(46.67 \%, 42 \%)$ which is consistent with other studies. ${ }^{6-12}$ The most susceptible age group range of $18-27(52.66 \%, 48 \%)$ years in both sexes in both hospitals, which was similar to a study.13 In this study, antidepressant drugs were prescribed more in married people in both hospitals and is comparable to previous study.6,9,14 It was observed that married female, housewife, less educated, unemployed, lower income group from rural area generally attended in psychiatry OPD who are prescribed more antidepressant drugs during this period.

Major depression was the most common disorder encountered( 64\%, 58.66\%) followed by generalized anxiety disorder $(24 \%, 28.66 \%)$, obsessive compulsive disorder $(7.33 \%, 10 \%)$, chronic pain $(4.67 \%$, $2.67 \%$ ) in $\mathrm{DMCH}$ and SSMCH respectively which is consistent with other study. ${ }^{10}$

Among the different antidepressants, SSRIs $(54 \%, 60 \%)$ were the most commonly prescribed followed by TCAs $(28 \%, 20 \%)$, SNRIs $(10 \%, 4.66 \%)$ and atypical antidepressants $(8 \%, 15.33 \%)$ in both $\mathrm{DMCH}$ and $\mathrm{SSMCH}$ respectively. This findings is consistent with other several studies. 1,6,8,11-12,14-16 Among SSRIs, Sertraline (58.02\%, 70\%) was 
most widely used followed by escitalopram (20.98\%, 22.22\%), citalopram (12.34\%, $4.44 \%)$ and fluoxetine $(8.64 \%, 3.33 \%)$ in $\mathrm{DMCH}$ and $\mathrm{SSMCH}$ respectively which is consistent with other studies. 1,13

TCAs were the second most prescribed with amitriptyline $(61.90 \%, 43.33 \%)$, clomipramine $(16.66 \%, 40 \%)$ and imipramine $(21.42 \%, 16.66 \%)$ in $\mathrm{DMCH}$ and $\mathrm{SSMCH}$ respectively. The use of TCAs in this study was much lower than SSRIs, as reported in another study. ${ }^{12}$ Venlafaxine among SNRIs $(10 \%, 4.66 \%)$, and Mirtazapine among atypical antidepressants $(8 \%, 15.33 \%)$ were prescribed in $\mathrm{DMCH}$ and $\mathrm{SSMCH}$ respectively to few patients which was similar with another study. ${ }^{6}$ Along with antidepressants most of the patients were also prescribed anxiolytics, antipsychotics, others (antiulcerants, laxatives, vitamins) in both hospitals. This is consistent with other studies where benzodiazepines were most commonly prescribed to relieve the anxiety symptoms. ${ }^{1,3,6,13}$

Regarding the polypharmacy, there was no polypharmacy in our study. Our observation in $\mathrm{DMCH}$ and SSMCH over $(20.66 \%, 24 \%)$ of prescriptions contained single drug, $(48.66 \%$, $45.33 \%$ ) contained two drugs, (16.67\%, $25.33 \%$ ) contained three drugs and only $(14 \%, 5.33 \%)$ of prescriptions contained four drugs respectively. This is consistent with other studies where polypharmacy was avoided. ${ }^{10,16}$ Total 336 drugs were prescribed for 150 patient encounters in $\mathrm{DMCH}$ and total 318 drugs were for 150 patient in $\mathrm{SSMCH}$, making the overall average number of drugs per encounter 2.24 and 2.12 respectively which is comparable with the findings of other studies where it ranged from 2 to 3 drugs per prescription. ${ }^{8,13}$ Format of the prescriptions with respect to dose, duration, frequency was complete in $100 \%$ of the prescriptions of psychiatric OPD of both hospitals.

In the present study our observation was that, hundred percent $(100 \%)$ drugs were prescribed by their brand names in both hospitals which was not in accordance with the $\mathrm{WHO}$ guidelines as rational prescribing requires generic names of drug. This is consistent with another study. 6 In drug formulation practices in our study we observed that, the percentage of prescriptions with an oral drugs accounted for $100 \%$ where an injection encountered was $0 \%$ in hospitals which is in concordance with other studies. $6,7,13$

Regarding drug prescribing from essential drug list (EDL) of Bangladesh 2008, our observation was that, in $\mathrm{DMCH}$, only 126 drugs $(37.5 \%)$ out of 336 drugs in 150 prescriptions and in $\mathrm{SSMCH}$, only 81 drugs $(25.47 \%)$ out of 318 drugs in 150 prescriptions were prescribed from the EDL of Bangladesh, 2008 which did not meet the standard criteria of prescribing medications from an EDL. This is consistent with other studies where percentage of prescribing from EDL was low. 7,13 Among our main prescribing antidepressant drugs only amitriptyline is enlisted in EDL. Other drugs were ascorbic acid, diazepam, magnesium hydroxide, omeprazole, Vitamin B-Complex.

On the basis of our observation, it may be mentioned that overall prescribing pattern of antidepressants in psychiatric OPD was good which may be considered as an effort to improve the quality of health care services.

\section{Conclusion}

Depression is one of the major public health concern worldwide and Bangladesh is not an exception. As per objective of the present study, it may be concluded that the overall prescribing pattern of antidepressant drugs among $\mathrm{DMCH}$ and SSMCH are almost similar in accordance with $\mathrm{WHO}$ prescribing indicators despite small deviation in prescribing practices. Regarding antidepressant therapy, prescriptions were complete in respect to dose, duration and frequency. The average number of drugs per prescription was higher than recommended by WHO. Generic name was ignored and list of essential drugs was followed partially. Although prescribing pattern of antidepressant drugs were similar in two teaching hospitals but list of essential drugs was followed more in $\mathrm{DMCH}$ than SSMCH. 


\section{References:}

1. Chen C, Si TM, Xiang YT, Ungvari GS, Wang CY, He YL, et al. Prevalence and prescription of antidepressants in depression with somatic comorbidity in Asia: The research on east Asian psychotropic prescription patterns study. Chin Med $\mathrm{J}$ (Engl). 2015;128(7):853-8.

2. Mohit $M$, Maruf $M$, Ahmed $H$, Alam M. Depression and Physical Illnesses: an Update. Bangladesh Med J. 2012;40(1):53-8.

3. Amuthaganesh $M$, Suhasinee $S$, Mathialagan S. Pattern of antidepressant utilization at a tertiary hospital in Malaysia (2009-2011). Asian Journal of Pharmaceutical and Clinical Research. 2012;5 (SUPPL.4):43-46.

4. Lamichhane DC, Giri BR, Pathak OK, Panta OB, Shankar PR. Morbidity profile and prescribing patterns among outpatients in a teaching hospital in Western Nepal. McGill J Med. 2006;9(2):126-32.

5. World Health Organisation. Introduction to drug utilisation research. Oslo: World Health Organisation, 2003.

6. Dutta S, Kaul V, Beg M, Sindhu S, Singh $\mathrm{N}$, Dutta $\mathrm{S}$, et al. A psychotropic drug use study among depression patients attending private psychiatric practitioners of Dehradun, Uttarakhand. Int J Med Sci Public Heal [Internet]. 2015;4(5):1. Available from: http://www.scopemed.org/?mno=177910

7. Lahon K, Shetty HM, Paramel A, Sharma G. A Retrospective Drug Utilization Study of Antidepressants in the Psychiatric Unit of a Tertiary Care Hospital. J Clin Diagnostic Res. 2011;5:1069-75.

8. Memon A, Patel K. Drug use pattern of antidepressant agents in psychiatric patients-A prospective study. Nhl J Med Sci. 2013;2(2):33-6.

9. Mishra S, Swain T, Mohanty M. Patterns of prescription \& efficacy evaluation of Antidepressants in a tertiary care teaching hospital in Eastern India. Asian J Pharm Clin Res. 2012;5(SUPPL. 3):193-6.

10. Mukherjee S, Sen S, Chatterjee SS, Era N, Ghosal M, Tripathi SK. Adverse drug reaction monitoring of antidepressants in the psychiatry out patient department at a tertiary care teaching hospital in India: A cross $\square$ sectional observational study. Eur J Psychology \& Educational Studies. 2015; Vol 2 / Issue1.

11. Motevallyzadeh HR, Baneshi MR, Rameshk M, Nakhaee N. Prescribing Pattern of Antidepressant Drugs among General Practitioners and Psychiatrists $\square$ : a study from Iran. 2013;1-4.

12. Sultana J, Italiano D, Spina E, Cricelli C, Lapi F, Pecchioli S, et al. Changes in the prescribing pattern of antidepressant drugs in elderly patients: An Italian, nationwide, population-based study. Eur J Clin Pharmacol. 2014;70(4):469-78.

13. Ghosh S, Roychaudhury S. Prescribing pattern of antidepressant drugs in a tertiary care hospital of eastern India. J Chem Pharm Res. 2014;6(6):2593-7.

14. Avanthi E, Somashekar H, Kumar L, Sushma H, Sudarshan C, Raja B. Prescribing pattern of antidepressants in psychiatric unit of a tertiary care hospital. International Journal of Basic and Clinical Pharmacology [Internet]. 2014; 3(4): 667. Available from: http://www.scopemed.org/?mno=161040

15. Ahmad F, Singh PP, Manoj, Kumar A, Gaur RK. Drug prescribing pattern for major depressive psychosis patients in geriatric clinic of a teaching hospital in Northern India. Int J Pharm Pharm Sci. 2013;5(2):269-72.

16. Thakkar KB, Jain MM, Billa G, Joshi $A$, Khobragade AA. A drug utilization study of psychotropic drugs prescribed in the psychiatry outpatient department of a tertiary care hospital. J Clin Diagnostic Res. 2013;7(12):2759-64. 